\title{
Sustainable Educational Ecosystems: Bridging the Gap between Educational Programs and in- Demand Market Skills
}

\author{
Michael Deev, Leyla Gamidulaeva*, Alexey Finogeev, Anton Finogeev, and Sergey Vasin \\ Penza State University, Krasnaya Str., 40, 440028 Penza, Russia
}

\begin{abstract}
With the technological advancements, academics and educational programs' developers need to provide students with competences and skills that match the market's demand. The article considers the problems of updating educational programs and content, taking into account changing requirements of standards and employers for qualifications and competencies of specialists. It is shown that the updating process in transition to an innovative and digital economy is associated with the transition to the convergence model of education. The authors have developed a basic model for updating educational programs based on the convergence approach. The presented framework benefits both academia and industry by enhancing the programs and therefore bridging the skills gap.
\end{abstract}

\section{Introduction}

Quality education is stated as one of the Sustainable Development Goals (SDGs) [1]. The SDGs put forward the imperative to "ensure inclusive and quality education for all and promote lifelong learning" [1]. Quality education may be considered as the key driver of sustainable development $[2,3,4,5]$ in both the developing and the developed countries.

The education sphere is not immune to advances in newly developed information and communication technologies. With the technological advancements, academics and educational programs' developers need to provide students with competences and skills that match the market's demand. In the context of constant changes, when the obsolescence of technical solutions and business models happens for several years, specialists need to constantly learn new business practices and skills, and quickly build up competencies. A systematic monitoring of the market is needed in order to ensure the alignment between acquired educational programs outcomes and required market skills.

The development of mobile communication technologies and the transition to $4 \mathrm{G}$ and $5 \mathrm{G}$ generation network provides the possibility of ubiquitous access to educational content. At the same time, the information learning environment becomes open and goes beyond the boundaries of classrooms and educational institutions [6]. In such conditions, the concept of

${ }^{*}$ Corresponding author: gamidullaeva@,gmail.com 
the educational ecosystem is gaining popularity [7], aimed at developing students' competencies, which are in demand in the new post-industrial economy, and has the following features: plasticity, variability, consistency, interactivity, and modularity. Educational ecosystems bring together various stakeholders, including representatives of business, society and the state, and are focused on improving learning processes in order to harmonize the interests of all participants on the principles of cooperation and partnership.

Training of specialists in an open ecosystem's environment requires modernization of existing approaches to learning [8]. We are talking about the convergence of approaches to training specialists in different subject areas based on the model of convergence education [9]. An open information and educational ecosystem's environment with an intelligent mechanism for personalizing the process of training and retraining specialists is a tool for the transition to the concept of convergence education [10]. Artificial intelligence tools are designed for adaptive management of updating educational resources (content) and educational programs corresponding to the requirements of the labor market and innovative economy.

Constant updating is necessary in order to keep pace with changes in the society, to meet new requirements for specialists in the context of digitalization of most human life processes. The purpose of updating is to improve qualification and/or retraining of specialists having got specialized secondary or higher education in educational institutions, taking into account new requirements of employers for their competencies [11].

In terms of the multi-agent approach, the educational process can be represented as the interaction of many agents (actors) in a self-developing, open and changeable environment at different lifecycle stages of specialists' training [12,13]. The actors are federal and regional ministries and departments, educational institutions, employers, administrators and methodologists of the educational process, teachers, students, libraries, etc. The sustainability of the educational ecosystem can be defined as the ability to continuously maintain information interaction between actors, to ensure their professional activities in accordance with the systemic principles of balancing educational business processes. The main actors and their functions are presented in Table 1.

Table 1. Examples of educational ecosystem's actors and their functions

\begin{tabular}{|c|c|c|}
\hline Actors & Main roles & Main functions \\
\hline $\begin{array}{l}\text { Enterprises, } \\
\text { institutions, } \\
\text { entrepreneurs }\end{array}$ & $\begin{array}{c}\text { Human } \\
\text { resources customer }\end{array}$ & $\begin{array}{l}\text { Synthesis and formulation of the required } \\
\text { competencies } \\
\text { Search and selection of graduates and specialists } \\
\text { with the required competencies }\end{array}$ \\
\hline $\begin{array}{l}\text { Educational } \\
\text { institutions, } \\
\text { educational } \\
\text { Internet sites }\end{array}$ & $\begin{array}{l}\text { Educational resources } \\
\text { integrator } \\
\text { Learning process } \\
\text { administrator }\end{array}$ & $\begin{array}{c}\text { Integration of educational resources and } \\
\text { technologies } \\
\text { Alignment with educational and professional } \\
\text { standards } \\
\text { Management of the educational process } \\
\text { Ensuring interactions between actors in the } \\
\text { information and educational environment }\end{array}$ \\
\hline $\begin{array}{c}\text { Ministries } \\
\text { and departments }\end{array}$ & $\begin{array}{l}\text { Regulator of the } \\
\text { educational process }\end{array}$ & $\begin{array}{l}\text { Certification and accreditation of educational } \\
\text { institutions } \\
\text { Development of educational standards, } \\
\text { Allocation of financing }\end{array}$ \\
\hline $\begin{array}{l}\text { Electronic } \\
\text { libraries and } \\
\text { Internet } \\
\text { resources }\end{array}$ & $\begin{array}{c}\text { Educational resources } \\
\text { integrator }\end{array}$ & $\begin{array}{l}\text { Accumulation and integration of educational } \\
\text { resources } \\
\text { Providing access to educational resources }\end{array}$ \\
\hline
\end{tabular}


Continuation of Table 1. Examples of educational ecosystem's actors and their functions

\begin{tabular}{|c|c|c|}
\hline $\begin{array}{l}\text { Lecturers, } \\
\text { teachers, } \\
\text { methodologists }\end{array}$ & $\begin{array}{l}\text { Generator of } \\
\text { educational content } \\
\text { and technologies } \\
\text { Executor of the } \\
\text { educational process }\end{array}$ & $\begin{array}{l}\text { Synthesis of educational content, } \\
\text { Implementation of the educational process }\end{array}$ \\
\hline Student & $\begin{array}{l}\text { Consumer of } \\
\text { educational content } \\
\text { and technologies }\end{array}$ & $\begin{array}{l}\text { Ensuring resource utilization processes as long as } \\
\text { possible with the ability to regenerate project } \\
\text { products into other projects }\end{array}$ \\
\hline
\end{tabular}

In accordance with system and synergetic approach, there are elements of a selforganization process in an ecosystem. They are possible when there is an open feedback mechanism for all participants. This mechanism makes it possible to implement adaptive adjustment and updating of educational programs and content, taking into account the requirements for the employers' competencies for specialists, and to reconcile them with the requirements of professional and educational standards.

\section{Materials and Methods}

Convergence is known as the integration of properties and features of various processes and phenomena as a result of interpenetration and functioning of complex systems under certain conditions. Integration of social, cognitive and information technologies in the open education system allows us to talk about a new convergence model of the educational process. To implement the model of convergence education, it is necessary to create an information and educational environment with intelligent methods for managing the process of training a specialist. The environment should support the integrated learning methodology STEAM (Science, Technology, Engineering, Arts, Mathematics) [14]. The methodology makes it possible to apply a number of new approaches to acquiring knowledge based on a single platform that promotes the development of similar competencies in different subject areas of knowledge.

In fact, the convergence approach to teaching is to ensure the merger of educational trajectories of different specialties in accordance with the integrating requirements of professional standards and employers. In particular, the transition to the digital economy has led to the fact that the set of competencies of specialists in different professions should include competence from the field of information, telecommunications and computing technologies. The concept of convergence in education requires the integration of educational resources and technologies in single information and learning environment with intelligent mechanisms for the synthesis of personalized training trajectories and monitoring of acquired competencies with the possibility of adaptive adjustment of the training process to changing external factors [15]. These factors include, for example, job change, changes in labor functions, emergence and implementation of innovative and digital technologies, etc. Therefore, in the learning process, specialists might acquire new competencies, which is associated with the updating of educational programs and content in the process of managing their lifecycles.

The initial data for the analysis of competence requirements for vacancies in the region are as follows:

1. geospatial data on the location of employers and time frames for the relevance of vacancies; 
2. data on demand and supply of vacancies in the regional labor market (formed on the basis of the statistical analysis of posting and views of advertisements, the number of occupied vacancies, etc.);

3. data on offered and real wages for vacancies;

4. an assortment list of requirements for specialists at the moment;

5. an assortment list of competencies that specialists acquire in educational institutions at the moment;

6. a list of educational programs and resources in regional educational institutions with an expert assessment of complexity for their updating.

Information for updating educational programs and content can be found in open sources on the Internet, such as sections with vacancies on the websites of enterprises, recruiting agencies, labor exchanges, message boards, on forums, in chats and groups of social networks and messengers, in rich site summary (RSS) mailing lists, etc. Due to the huge number of possible information sources on the Internet, Big Data technologies and Data Mining intelligent analysis are in demand for monitoring and analyzing data. Big Data technologies require preliminary preparation or consolidation.

\section{Results and Discussion}

To update educational programs, the authors have developed models of lifecycles of educational programs (EP).

A model of the educational program actually sets the trajectory of learning process of a specialist in information and educational space, where he acquires specific competencies and reaches a qualification level in accordance with the professional and educational standards guaranteed by the program. Each discipline in the EP is associated with ELR, which help a specialist acquire necessary competencies that should meet the requirements of educational standards and employers (Fig. 1).

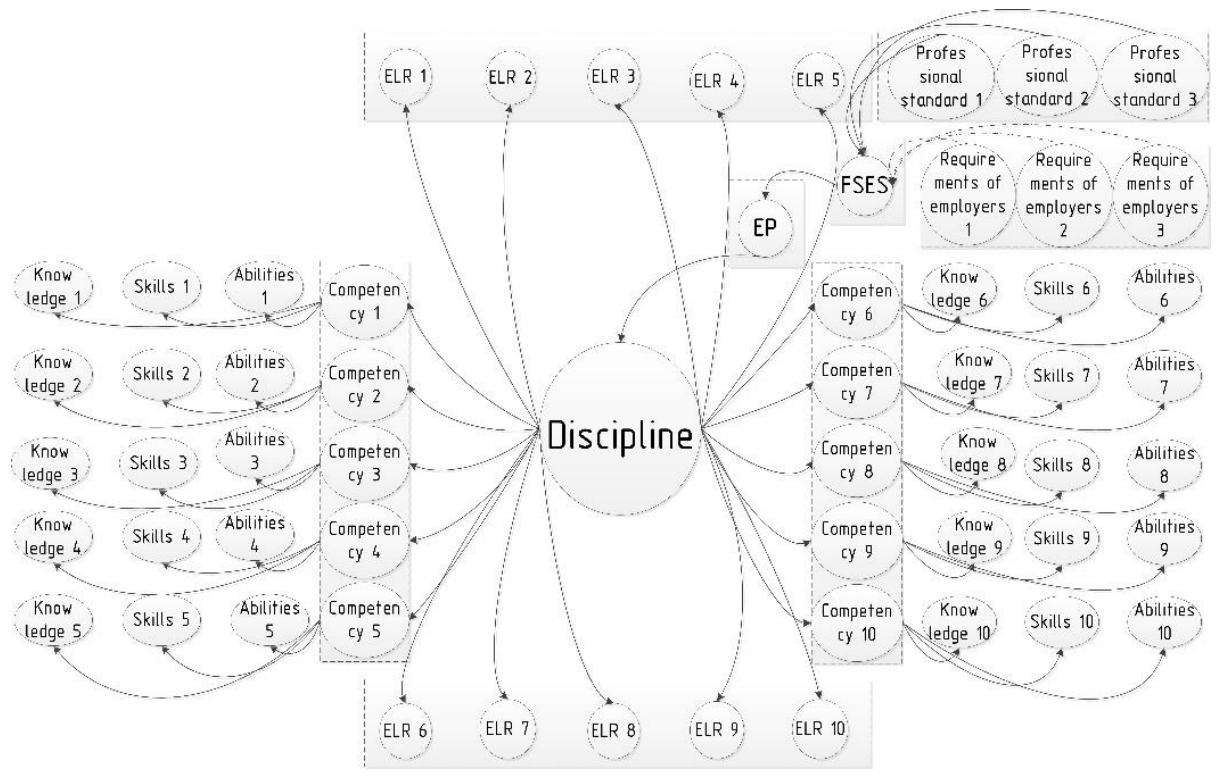

Fig. 1.Model of a discipline in the educational process 
A typical model of the EP lifecycle corresponds to the class of iterative development models [16]. Let's consider a model with an updating stage, which evaluates the degree of convergence of an updated program with programs of other specialties (Fig. 2).

The following tasks are solved within the framework of the convergence approach at the updating stage:

- collection, extraction and analysis of new requirements for the competencies of specialists from the changed professional and educational standards,

- collection, extraction, consolidation and analysis of new requirements of employers for the competencies of specialists in regional labor markets,

- comparative analysis (benchmarking) of the consolidated requirements of standards and employers to specialists from different fields of knowledge and areas of activity, and assessment of the degree of their convergence,

- verification of educational programs for compliance with the new requirements of standards and employers,

- comparative analysis (benchmarking) of programs for training specialists from different fields of knowledge and areas of activity, and assessment of the degree of their convergence,

- ranking and selection of programs according to the maximum degree of similarity for the synthesis of unified programs of convergence training of specialists for different fields of activity.

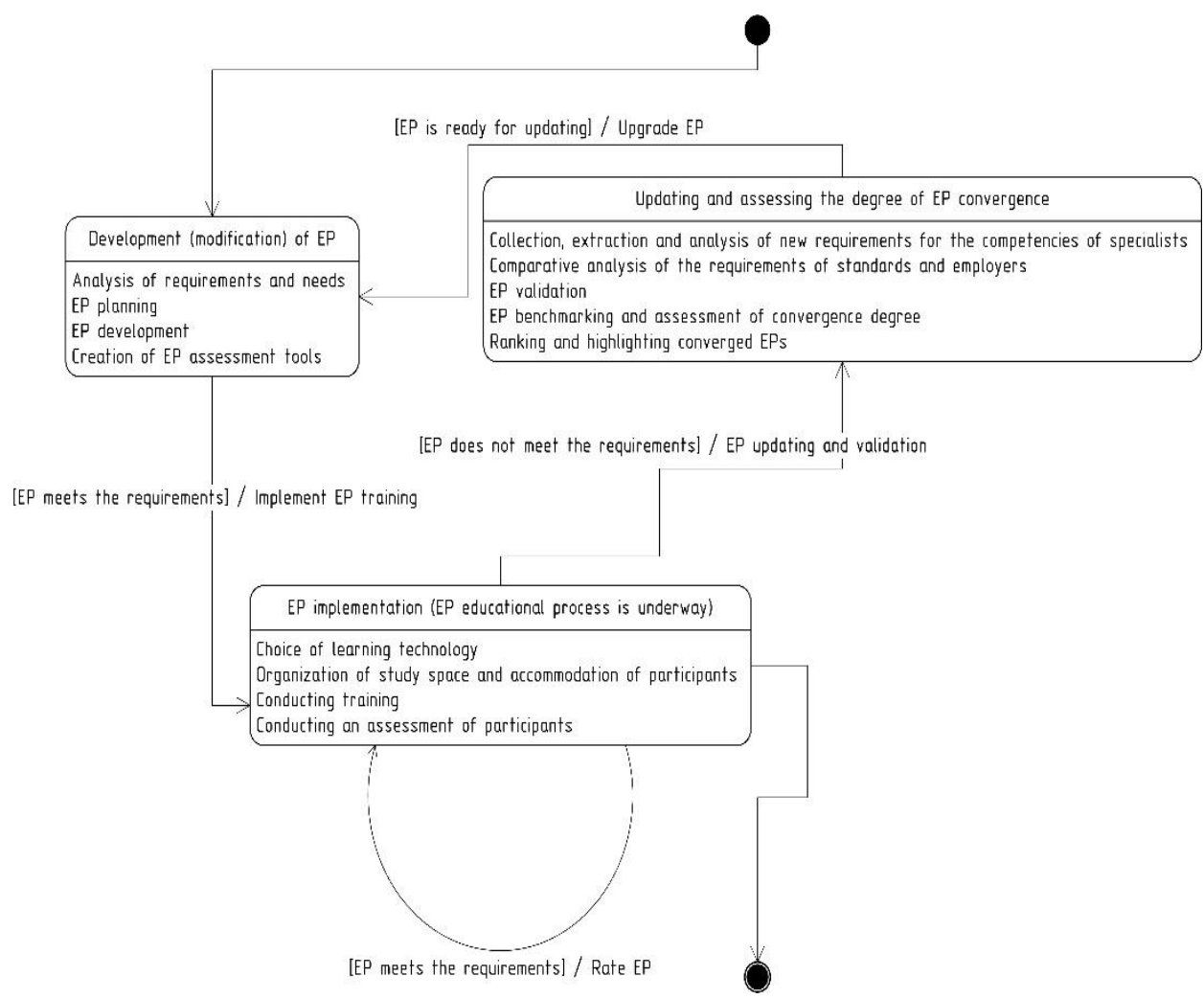

Fig. 2.Model of the EP lifecycle with an updating stage

Here are the external factors affecting the updating process:

1. information resources and open access materials used to update it; 
2. an updated educational program, which is used to customize the educational content to obtain new competencies in accordance with the requirements of standards and employers;

3. various learning resources with similar content, which are used to obtain similar or analogous competencies and contain common (convergent) material for various disciplines in different subject areas;

4. additional requirements for educational content that arise in connection with the emergence and implementation of new educational technologies, for example, the requirement for the creation of an online lecture course for the system of open and distance education;

5. assessment tools for analyzing the degree of effectiveness of using educational content to obtain the required competencies in the process of training a specialist.

The output parameters are updated sets of electronic learning resources, technologies and techniques for working with them, tools for managing content in the process of its publishing in the information and learning environment, providing personalized access, assistance in working with it, and assessing the acquired competencies.

Achievements in the field of creating mechanisms for managing educational processes confirm the need for creation and implementation of the proposed approach [18]. In particular, in [19], a similar teaching system is proposed, which includes intelligent and interactive content with the possibility of personalization and adaptive adjustment of the education process. The key possibilities for intellectualizing the teaching process and the problems of developing smart educational environments are discussed in [20].

The authors proposed to solve the problem of managing educational processes in the developed smart environment on the basis of synchronization and updating of educational programs and content with adaptive adjustment to the changing requirements of educational standards and employers.

\section{Conclusions}

To promote sustainable development and to introduce the necessary changes in the current digital transformation process, it is necessary to implement new ICT solutions that support innovation. One of the most pressing topics these days in both academia and industry is training specialists according to the requirements of the market. The information learning environment becomes open and goes beyond the boundaries of classrooms and educational institutions. In such conditions, the concept of the educational ecosystem is gaining popularity $[7,20]$.

The proposed in this paper approach is an attempt to "operationalize" the educational ecosystem model in terms of solving the problem of updating educational programs and content using the advanced technologies. As a result, it will ensure the quality education and sustainable growth and development.

A research analysis in this area has shown that there are a number of problems associated with obtaining the required competencies by specialists, since educational institutions do not have time to change educational programs and content in transition to an innovative and sustainable economy. Problems are associated with incorrect employers' formulation of competencies, lack of qualified specialists, inability to obtain the required competencies in regional educational institutions, dynamics of changes in the requirements of the real sector of the economy, time lag between the emergence of new requirements for competencies and changes in educational programs and content, duration of the process of training specialists according to new requirements, the need to harmonize changes with the requirements of professional and educational standards. 
The concept of convergence in education requires the integration of educational technologies in a single information and learning environment with intelligent mechanisms for monitoring and updating educational programs and content for adaptive adjustment to changing external factors.

The convergence approach to updating educational programs and content is being introduced and tested in educational ecosystem of Penza State University (Penza, Russia).

\section{Acknowledgements}

The work outcomes were obtained with the financial support of the Russian Foundation for Basic Research under grants No. 19-013-00409-a, 18-07-00975-a, 18-010-00204-a. The research results presented in Section 3 were obtained at the expense of the Russian Science Foundation (project No. 20-71-10087).

\section{References}

1. United Nations Development Programme. Sustainable Development Goals, http://www.undp.org/

2. F.C. Saunders, A.W. Gale.Br. J. Educ. Technol. 43 (2012)

3. E. Szekely, M.J. Mason. Educ. Policy (2018)

4. C. Bereiter, M. Scardamalia. Routledge: London, UK (2018)

5. A. Visvizi, M. Lytras, L. Daniela. Emerald Publishing: Bingley, UK (2018)

6. Bonk, C.J. USDLA Journal, 16(1) (2002), http://www.usdla.org

7. Luksha, P. Present5 (2015), http://present5.com/

8. Hussin, A. International Journal of Education \& Literacy Studies, 6(3) (2018).

9. M.V. Deev, A.G. Finogeev, A.A. Finogeev, L.A. Gamidullaeva, A.M. Bershadsky. L.R. Fionova, EAIT.1 (2019)

10. M.V. Deev, T.V., Glotova, I.G. Krevskiy, Knowledge-Based Software Engineering, 466 (2014)

11. C. Macal, M. North, Simulation 4 (2010)

12. E.Bonabeau, PNAS (2002)

13. M.C. Roco, W.S. Bainbridge, B. Tonn, G. Whitesides (Eds), Springer (2013).

14. L. Dorothy, M. Schmalz, C. Janke, L. Laura, Journal of Leisure Research, 50(5) (2019)

15. B. Daniel, British Journal of Educational Technology, 46(5) (2014)

16. S. Fry. Education Technology, https://edtechnology.co.uk/(2019)

17. P,G, Lister.Smart Learn. Environ, 5 (2018)

18. B. Vesin, K. Mangaroska, M. Giannakos. Smart Learn. Environ. 5, 24 (2018)

19. B. Gros. Smart Learn. Environ, 3 (2016)

20. T. Tolstykh, L. Gamidullaeva, N. Shmeleva, Y. Lapygin, Sustainability, 12 (2020) 